\title{
A Natureza Épica do Cristianismo

\author{
em De Gestis Mendi Saa
}

\author{
Josefa Nunes Tavares \\ Universidade Severino Sombra, Centro de Letras Ciências Sociais \\ Aplicadas e Humanas, Curso de Letras
}

Resumo: Este trabalho desenvolve a temática do Discurso Épico do Cristianismo, partindo do poema latino De Gestis Mendi Saa, atribuído ao padre Joseph de Anchieta S. J. A estratégia centra-se nas manifestações épicas e no entrelaçamento da mitologia pagã com a cristã, na criação de uma nova epopéia dentro dos moldes renascentistas. A análise observa o tipo de herói comandado por inspiração divina, correspondendo a representação de Cristo Rei. Nesse tipo de herói encontra-se a força de Anchieta na inovação de uma epopeia, de cunho cristão, em expressão latina, inserida no século XVI, no Brasil, pleno de conquistas materiais e espirituais. $O$ estudo do poema retrata uma guerra sangrenta dos soldados de Cristo em extermínio aos infiéis. Ressalta-se, na análise, um contraste medieval, destacando-se a ideia de “ vingança” - signo gerador de todas as façanhas de Mem de Sá.

Palavras chaves: Catequese. Poder. Cristianismo.

\section{The Epic Discourse of Christianity in De Gestis Mendi Saa}

\begin{abstract}
This essay developsthe theme of the Epic Discourse of Christianity, from the latin poem De Gestis Mendi Saa, attributed to Father Joseph de Anchieta S.J. The strategy is centered itself in the epical manifestations and in the interlacement between the pagan mythology the Christian one, in the Creation of a new epopee according to renascence Standards. The analysis observes the king of hero commanded by divine inspiration, corresponding to a representation of the Christ- King. In this king of hero lays the poetical strength of Anchieta which stands for a inovation in epopee of Christian stamp, in latin expression, inserted in the Sixteenth Century, in Brazil, full of material and spiritual conquests. The study, of thew põem pictures a bloody war of Christian soldiers in extermination of the infidels. The analysis emphasizes a medieval contrast, underlining the Idea of "vengeance" - sign generator of all deeds by Mem de Sá.
\end{abstract}

Keywords: Epical manifestations. Power. Christianity 
Artigo de Demanda Contínua

\section{Introdução}

É importante ressaltar que seguiremos o texto original em latim, acompanhado da tradução vernácula pelo padre Armando Cardoso, conforme primeiro item das referência bibliográficas. As indicações de página referem-se à mencionada obra

O poema apresenta as divisões de uma epopeia, mas com uma parte invertida: a dedicatória vem abrindo o poema, onde o poeta/narrador enaltece o herói, atribuindo toda a glória de seus feitos a Deus, o único capaz de tanta grandeza.

No início do Livro I, surgem a proposição e a invocação, dirigidas a Cristo, onde se entrelaçam o ser histórico e o mitológico; logo em seguida começa a narração, enfocando, inicialmente, a bravura de Fernão de Sá e a sua morte, para depois, a partir do Livro II, iniciar a narração propriamente dita dos feitos de Mem de Sá, fechando a epopeia com um canto de louvor a Cristo Rei.

Na Epístola Dedicatória, o poeta dirige-se a Mem de Sá, elevando-o à condição de herói. Apesar de os tempos passados revelarem os fatos já consumados, sabe-se que não há o distanciamento no tempo: os fatos são contemporâneos ao poeta e o herói encontra-se ainda vivo. Devem-se registrar as conclusões da Epístola Dedicatória, segundo o padre Armando Cardoso:

O autor é um religioso culto, humanista em todo sentido da palavra. Escreve sob a impressão recente dos fatos de 1560, com a suspeita fundamentada de ser esse o último ano de governo de Mem de Sá, como a agradecer-lhe os resultados de seus esforços, augurando-lhe as recompensas divinas da santidade e da glória eterna.(p. 9).

Estamos, portanto, diante de um poema épico escrito por um religioso que incorporou em seu discurso vários elementos da mitologia pagã, sem trair a sua formação missionária e cristã. Não é de se espantar tanta alusão à mitologia pagã, em um discurso jesuítico, já que no ano 319, o Cristianismo começou a assimilar ritos e costumes pagãos. O Natal, por exemplo, passou a ser comemorado no dia 25 de dezembro, dia do deus sol; o culto à Virgem Maria substitui o de Cibele, mãe dos deuses romanos.

\section{Desenvolvimento}

O poema, De Gestis Mendi Saa, por ser uma epopeia, foge aos modelos antigos e renascentistas que invocavam as musas pagãs. O que se observa nesse poema é o desfile de uma galeria de mitos pagãos sem forças para decidir os destinos dos homens. Evidencia-se, portanto, a assimilação do paganismo pelo cristianismo.

Apesar das referências à mitologia pagã, isto não significa que Anchieta tenha aderido aos conceitos pagãos. Toda entidade pagã surge como recursos de estilo, prenunciando, provavelmente, o modelo renascentista que culminaria com Os Lusíadas.

A guerra contra os índios e os protestantes carrega em si o espírito de Cruzada, não só para o povo português, como para o próprio poeta, acostumado ainda às leituras dos livros de cavalaria e das lutas contra os mouros na Península Ibérica. Tanto Mem de Sá como Fernão de Sá refletem a marca de conquistadores quinhentistas, mas deixam transparecer em suas ações o selo indelével de cavaleiros medievais. 
Ao longo do poema, a mitologia pagã surge como um recurso retórico, reforçando a tese de que o discurso épico do cristianismo encontra-se impregnado de elementos pagãos, destituídos de poderes, mas servindo como elemento importante na caracterização de uma epopéia cristã.

Para não fugir aos ideais renascentistas nos quais estava inserido, Anchieta, consciente ou inconsciente, entrelaça vários estilos (medieval, renascentista, maneirista e barroco) na criação de uma epopéia, moldada ao século XVI, em "terras brasílicas". Por sua vez, Cristo entrelaça o ser histórico e mitológico, revelado através dos rituais do catolicismo. O uso da primeira pessoa denuncia a presença do poeta/narrador como um soldado de Cristo, lutando ao lado dos portugueses e, ao mesmo tempo, exaltando Mem de Sá por representar o herói invisível capaz de vencer todas as fortalezas.

Não faltam em Mem de Sá a nobreza, a inteligência, a experiência através dos anos vividos, o caráter, a beleza da alma, o amor e o temor a Deus, a fé em Cristo - um herói épico perfeito, dentro da concepção exigida no século XVI, ainda sob forte influência medieval.

As palavras de Mem de Sá, dirigidas ao filho, denuncia o "universo mítico" que interferirá nas ações de ambos: "À luta pois com braço forte, e no fundo do peito / gravado o nome do Senhor que governa o universo!" (p.61). Certos de que estavam sob a proteção divina, os heróis nada temem, porque os espera uma recompensa maior: a glória celeste. A guerra é bárbara e sangrenta, e a palavra "vingança" permeia todo o poema instigando os heróis à luta contra os inimigos da igreja. É uma nova guerra santa que se ergue como justificativa para os abusos da colonização.

O narrador chega a extremos e, em seu discurso, reflete-se a ideologia da Coroa Portuguesa: "comprando com o sangue a vitória da pátria." (p.71). "Vitória da Pátria" seria sinônimo de derrota indígena. $\mathrm{O}$ discurso anchietano comove, impressiona pelas palavras fortes de morte sangrenta em nome de Cristo. O índio, por sua vez, é retratado como um ser diabólico, que ameaça os domínios de Cristo e os seus escolhidos. Há, portanto, todo um panorama de justificativa para a guerra contra os indígenas e a sua possível extinção, caso não se rendessem aos ditames do povo português.

As descrições de guerra são imensas e intensas de ambos os lados. Daí a presença constante de Marte - o deus da guerra - tomado no poema por guerra.

Fernão de Sá é apresentado como um herói que, apesar de inebriado de sangue coloca "os olhos na derradeira vitória" (p.75). Assim como o sangue de Cristo salvou toda a humanidade, o sangue do herói também salvaria a vida de muitos cristãos. Vida e morte se entrelaçam na figura de Fernão de Sá: vida em Cristo e morte em Cristo. O importante não é a vitória terrestre, mas a glória celeste. Provavelmente para consolo do pai e aceitação do povo português, o narrador compara a morte de Fernão de Sá a de Cristo: o corpo foi vencido, mas a alma é invencível, conforme os versos: "e a honra imaculada de Cristo se imola / Nesse altar, para que sejam tuas feridas a vida de muitos.!" (p. 77).

A fidelidade de Fernão de Sá a Cristo reveste-se de uma auréola divina que o eleva à condição de imortal: o herói é imortal, já que a alma é invencível. Por trás de Fernão de Sá encontra-se o herói maior que justifica todas as proezas desses nobres portugueses: 
Cristo, o que comanda e determina todas as coisas. A morte de Fernão de Sá causa impacto e revolta e a sensação que fica das guerras descritas nos livros posteriores, é de que Mem de Sá veio "vingar " a morte do filho.

No poema fica evidenciado que, para combater os infiéis, Deus enviou um escolhido Seu, alguém que pudesse dominá-los sob o espírito de cruzada. Mem de Sá seria o escolhido de Deus, o messias que veio para aplacar a ira das gentes brasílicas e transformar a terra numa " terra prometida", relembrando episódios do Velho Testamento.

As palavras de Mem de Sá são as de um verdadeiro herói épico cristão, envolvido em forças divinas, revelando a sua verdadeira fortaleza. O herói não vacila, nem teme o inimigo. A sua coragem é proveniente da força de Deus e da fé em Cristo.

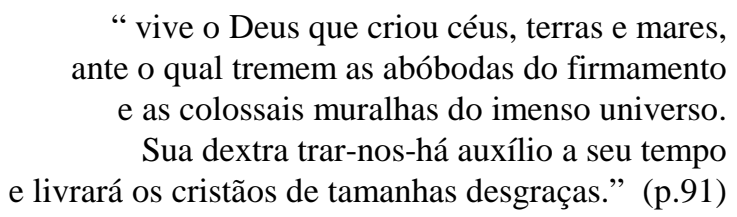

O discurso anchietano é comovente e eloquente. Constantemente são utilizados textos bíblicos como uma forma de justificar todos os feitos de Mem de Sá e, consequentemente, toda a empresa jesuítica: "Também a seus ouvidos soava / a voz de Cristo: 'força-os a entrar em meu santuário ! / que de povos diversos a minha casa transborde." (p.95)

Paralelamente a textos bíblicos e referências a Cristo, surgem entidades pagãs cristianizadas, cujo campo semântico está associado a "inferno", "diabo", "demônio": Anguis (Demônio), Bellua (diabo), Cerbereus (Demônio), Chaos (Inferno), Dis,Ditis (Diabo), Erebus (Inferno), Infernus/-alis (Inferno), Orcus (Inferno), Phelegethon (Inferno), Plutonius (do Diabo), Styx/Stygius (Inferno), Tartarus (Inferno), Tartareus (do Inferno), Tyrannus (Diabo). Com a revelação dessas entidades mitológicas, a epopeia ganha nova dimensão e adquire o caráter de Guerra Santa: a luta do Bem contra o Mal.

Com relação à inalterabilidade de ânimo, Helena Parente Cunha, tece os seguintes comentários:

$\mathrm{O}$ distanciamento entre o sujeito (narrador) e o objeto (mundo apresentado) favorece a inalterabilidade de ânimo do autor que não experimenta as oscilações do estado afetivo lírico. A trama pressupõe o afastamento que não significa o desaparecimento total do autor, presente através das observações pessoais e do entusiasmo demonstrado pelos fatos expostos. Camões não se conserva impassível ao se propor cantar os feitos dos "barões assinalados", que enfrentaram 'os mares nunca dantes navegados' 
No poema De Gestis Mendi Saa, essa inalterabilidade de ânimo desaparece a partir do momento em que o poeta narrador propõe cantar os feitos de Cristo Rei: "As glórias do Pai celeste e sua força divina / teu nome, ó Cristo Rei, e teus feitos gloriosos / começarei a cantar." (p. 55). Em seguida, invocando-o, o narrador se presentifica através do uso da primeira pessoa: "Tu, ó Jesus, ó clara luz do firmamento sereno, / ó fulgor sem ocaso, ó imagem do brilho paterno, / ilumina-me a mente cega, aclara-me a alma / com esplêndidos lampejos." (p.55). Não é de se admirar que o discurso de um poetamissionário, especialmente de um jesuíta como o padre José de Anchieta, não se extasiasse diante das obras divinas. E como não bastasse, o poeta constantemente se inclui entre os guerreiros, já proclamados como "soldados de Cisto": "Nossas armas gloriosas prostraram o feroz inimigo." (p.71). O narrador, portanto, participa indiretamente do mundo narrado através de suas reflexões pessoais sobre os fatos e diretamente, já que se inclui como um guerreiro, "um soldado de Cristo", apesar de não ter sido testemunha ocular dos fatos, os acontecimentos lhe foram passados por via escrita e oral.

De Gestis Mendi Saa se afasta dos padrões estabelecidos pelos antigos e se aproxima do modelo renascentista que se cristaliza em Os Lusíadas. Não seria exagero afirmar que o poema em estudo fundamenta a conceituação épica cristã, em terras brasílicas, servindo, provavelmente, de inspiração à obra camoniana.

Não existe a passagem do histórico para o maravilhoso, como se processa em $O s$ Lusíadas, mas se nota a total assimilação do paganismo pelo cristianismo. Os episódios líricos, onde o personagem ultrapassa a sua condição histórica e penetra no maravilhoso, não aparecem de forma a concretizar o poema como uma epopeia renascentista. Mas em se tratando de uma epopeia, cujo herói incorpora os dois planos (o histórico e o maravilhoso), os episódios líricos ganham uma dimensão cristã. Como exemplo, podese citar a morte de Fernão de Sá, que é comparada à de Cristo:

Quod te, magne, manet, iuvenis, decus! Omnia noscente Saecula te saevam Domini, patriaeque, patrisque Posthabuisse necem laudi; ignavique timoris Expertem, summis vitam obiecisse periclis, Atque tuo belli surgentem sanguine flammam Exstinxisse feri. Tibi Lusitana propago Hoc memor officium debere fatebitur, illi Quando morte tua vivunt, et pace fruuntur. (p. 76)

Tradução:

Grande jovem, eis tua glória! Os séculos todos saberão que preferiste morte cruel à desonra de Deus, da pátria e do pai, e que, desconhecendo o temor cobarde, expuseste a vida aos maiores perigos e apagaste, com teu sangue o incêndio da guerra que surgia ameaçador. Lembrar-se-ão os teus Lusos e confessarão agradecidos dever-te tal benefício: graças à tua morte, eles vivem e desfrutam de paz. (p. 77)

Fernão de Sá é comparado ao "cordeiro que fora imolado", portanto, também a sua 
morte é relatada de forma a glorificá-lo e de destacar o seu lugar entre os escolhidos. O marrador, inclusive, insinua que "os séculos todos / saberão que preferiste morte cruel à desonra / de Deus, da pátria e do pai...”. Assim como Cristo preferiu a morte na cruz para salvar toda a humanidade, cumprindo a vontade do Pai, assim também Fernão de Sá preferiu morte cruel a ter que desonrar o nome de Deus, da pátria e do pai. Cumprese, então, a trajetória de um herói que morreu para glorificar o seu povo. A expressão "os séculos todos saberão" também nos remete à morte de Cristo que ficou registrada através dos séculos.

Fernão de Sá pode ser comparado a Roland, que também lutou pelo imperador, pela pátria e pela religião e que não fugiu da morte, pelo contrário, entregou-se a ela. Assim como para Roland, honrar-se é morrer, o narrador coloca Fernão de Sá na mesma categoria desse herói medieval - morrer para salvar os cristãos. Ambos se remetem à figura de Cristo no que concerne ao tipo de morte.

A morte do bispo Pedro Fernandes Sardinha é narrada de forma a causar compaixão e desejo de vingança entre os lusos:

Hic finid magni qui primus praesulis oras Brasilles rexit, mitra sacrisque tiaris Et baculo insignis: iacet ingens amne cadaver Sanguine foedatum multo nudumque cruentos, Heu species indigna, artus sine honore sepulcri! (p. 140)

Tradução:

Foi este o fim do grande Prelado, quem por primeiro regeu as plagas brasílicas, de báculo, mitra e tiara.

Glorioso outrora, ei-lo estendido na margem do rio, cadáver inundado de sangue, e, ó cena horrível!

Todo despido, todo ferido, sem a paz do sepulcro.(p. 141)

Vê-se, portanto, através desses episódios, a presença do narrador, participando dos fatos narrados, carregando em si os sentimentos de todo um povo. A morte do bispo é descrita de forma terrível, causando, sem dúvida, impacto a toda a cristandade e, ao mesmo tempo, exigindo vingança, já que se tratava de um representante de Cristo.

Cristo se presentifica em vida e morte através de todos os atos praticados e sofridos pelo povo luso. O herói se reveste de uma auréola divina, mas não ultrapassa a sua condição histórica. Tanto Fernão de Sá, quanto Mem de Sá representam o herói invisível, que é Cristo. Esse tipo de discurso revela o espírito de cruzada, tão comum na Idade Média, resgatado no poema por um entrelaçamento de estilos típico da Renascença.

O maravilhoso pagão cede lugar ao maravilhoso cristão. Todo paganismo é assimilado pelo cristianismo e a epopéia se sustenta devido a essa assimilação, sem deixar de refletir o seu valor histórico, a imponência da narrativa nos atos guerreiros, as descrições intensas e bárbaras de guerra, e guerra sangrenta em nome da Cruz. Para reforçar, a mitologia cristã se ergue de tal forma no poema que se torna impossível excluí-la das grandes obras épicas. A proposição e a invocação definem o tipo de herói que será cantado em toda a narrativa, como uma forma de justificativa para todos os feitos de 
Artigo de Demanda Contínua

Mem de Sá.

A tomada do Forte de Villegaignon explica-se através do medo e do pavor que se apoderou dos franceses e dos tamoios. O narrador atribui tal fato à interferência divina devido às preces erguidas aos céus. O padre Armando Cardoso faz referência a um " cavalo de Tróia", que penetrou na fortaleza e expulsou os inimigos; por sua vez, o narrador menciona a atuação divina, enviando um "monstro horrendo, miserável e feio" para afugentar os inimigos de Deus. Sempre haverá uma explicação divina para justificar os fatos ocorridos.

Assim como Fernão de Sá possui algumas semelhanças com Roland, Mem de Sá pode ser comparado ao Cid. Importante ressaltar que tanto a Chanson de roland como $O$ Poema do Cid têm como temática a luta entre cristãos e mouros, revelando uma guerra sangrenta entre a cruz e a espada. O poema De Gestis Mendi Saa tematiza a luta entre fiéis (cristãos portugueses) e os infiéis (índios e protestantes), denunciando o mesmo espírito guerreiro. A comparação que pode ser feita entre Mem de Sá e o Cid é que ambos são heróis humanos, diferenciando-se dos heróis épicos tradicionais, que possuem poderes sobre-humanos. Tanto Mem de Sá quanto o Cid não ultrapassam a sua condição histórica, não pisam o campo do maravilhoso. Isso não significa que ambos não sejam heróis míticos. Essa mitificação se dá no campo das experiências humanas e não no sobrenatural. Assim como o maravilhoso na Chanson de Roland é considerado uma categoria estética, a fidelidade histórica no Poema do Cid e em De gestis Mendi Saa pode também ser considerada uma categoria estética.

Importante atentar para a relação público-herói em De Gestis Mendi Saa . Os ouvintes estão perto de Mem de Sá, exigindo um herói humano e um relato que sejam fiéis aos acontecimentos. Daí a morte de Fernão de Sá ter causado certo impacto ao povo português, a ponto de se criar uma edição econômica, onde se omite a sua morte. Comprova-se, então, que era inconcebível a morte de um herói. Vale afirmar, para fins de esclarecimentos, que Fernão de Sá não é o herói dessa epopéia. As suas proezas e a sua coragem são exaltadas nesse poema para consolo do pai. A impressão que se tem, portanto, é de que Mem de Sá veio vingar a morte do filho.

Em seus estudos sobre o poema, o padre Armando Cardoso o denomina de "essa verdadeira Eneida cristã", ressaltando, principalmente, a sua importância histórica. O poema narra os feitos de Mem de Sá, desde o início de seu governo até a tomada do Forte de Villegaignon, em 16 de março de 1560. Mas as façanhas de Mem de Sá não pararam por aqui. Perdurou durante doze anos a sua carreira de glória e de vitória contra os infiéis. A aliança feita entre Mem de Sá e os jesuítas da época fora a que causou maior número de mortandade entre os indígenas. O herói "compassivo" e "piedoso", conforme é tratado no poema, fora o causador de tanta destruição em nome de Cristo.

Mem de Sá fora nomeado em junho de 1556, por um período de três anos, tomando posse apenas em janeiros de 1558, logo, o ano de 1560 representava o terceiro de seu mandato. Como o padre José de Anchieta pretendia entregar-lhe pessoalmente o poema, teve pressa em acabá-lo, daí a não continuidade dos feitos de Mem de Sá. Mas esse fator não desmerece a riqueza poética do poema, nem o seu valor histórico. Apesar de ter-se dedicado aos fatos ocorridos até 1560, Anchieta soube pincelar, com a grandeza de um 
poeta épico, os fatos históricos que lhe vinham através de testemunhas escritas (cartas) e orais. Além da fidelidade histórica, sente-se, em todo o poema, a força criadora do poeta que, sem dúvida nenhuma, sofreu influências das grandes obras épicas.

O poema De Gestis Mendi Saa, escrito sob os céus dos “brasis", reflete uma luta de ideologia. O catolicismo se empenhou arduamente na doutrinação desses povos, impondo os seus valores, a sua crença, a sua cultura. Assim como no teatro anchietano, o poema em estudo representa, por excelência, uma propaganda do catolicismo, onde o povo português seria o escolhido para divulgar a nova doutrina a povos tão estranhos e de cultura tão distinta.

O padre Armando Cardoso denomina Anchieta de "o nosso Homero". Concordamos com essa expressão, já que o chamamos também de "o novo Homero em terras brasílicas", influenciados pelas palavras de Arnold Hauser quando diz que "cada época tem o seu Homero, a sua Chanson de Roland.", mas discordamos quanto à originalidade do poema, comentada pelo padre:

\footnotetext{
Anchieta foi acima de tudo humanista original, pelos assuntos novos que trouxe à literatura latina do Renascimento. E aí está talvez o seu maior mérito. É o seu aspecto indianista, é todo o mundo americano que ele revela ao mundo antigo, na língua de Virgílio, tão desembaraçadamente como se um romano fosse o espectador dessas cenas exóticas.(p. 28)
}

O poema encontra-se escrito em latim porque era a língua oficial da época (século XVI), principalmente nas universidades. Não é o aspecto indianista nem o mundo americano que ele revela ao mundo antigo, mas a luta dos soldados de Cristo contra os inimigos da fé.

Muitos estudiosos têm chamado essa epopéia de americana indianista, baseados nas palavras do padre Armando Cardoso, exímio estudioso das obras do padre José de Anchieta. Fica registrado, após o levantamento do poema e das partes que o compõem, que é uma epopeia cristã, em expressão latina, escrita em "terras brasílicas", onde o verdadeiro herói é Cristo Rei, denunciado na própria proposição. Como a mitologia cristã se diferencia da pagã, Mem de Sá representa o herói invisível, daí as suas façanhas serem grandiosas e motivo de júbilo para toda a cristandade portuguesa. $\mathrm{O}$ poetamissionário, para não fugir às regras que determinavam as grandes obras épicas, incorporou em seu discurso a mitologia pagã, já tomada, na época, pelo Cristianismo.

No tocante aos aspectos cristãos do poema, comenta o padre Armando Cardoso, ratificando as nossas palavras:

$\mathrm{O}$ argumento e a invocação do poema muito originalmente se dirigem a Cristo Rei: em toda a epopéia é o herói invisível que Mem de Sá representa. (p.34)

Tanto o herói como seu filho nos são apresentados em retratos de grande beleza física e moral, dotes humanos realçados pela fé profunda e zelo das almas. (p.35) 
A guerra não é para esses homens senão uma verdadeira cruzada contra os infiéis. Os heróis levam no braço e no coração a glória do nome de Deus. (p. 35)

E se encontram a morte no combate, ela será vida e vitória no triunfo imortal do céu. (p. 35)

O próprio Cristo os acompanha para resolver-lhes as dificuldades, como chefe invisível do exército cristão. (p.36)

Dizer que é uma epopeia americana indianista, é esquecer-se de como os índios foram massacrados durante o processo de colonização no Brasil. É o próprio padre Armando Cardoso quem afirma que a guerra era "uma verdadeira cruzada contra os infiéis". A vingança, na visão jesuítica contra os infiéis, era natural, já que estes ameaçavam o equilíbrio universal de toda a cristandade. A evangelização proclamada em "terras brasílicas" corresponde, no poema, a uma intervenção divina em terra pagã, pois os heróis são comandados por uma força divina que justifica toda guerra santa. Inicialmente os infiéis eram os índios, que deveriam ser subjugados ao domínio luso; depois, com a tomada do Forte Villegaignon, o protestantismo, que já se alastrava pelo mundo e correspondia a uma forte ameaça ao poder da Igreja. Merecem registro as palavras do padre Armando Cardoso quando diz que

\footnotetext{
Vibra em Anchieta o missionário jesuíta que transforma a espada justa e impoluta de Mem de Sá numa cruz invencível que rende os selvagens à doutrina de Cristo e expulsa o estrangeiro do solo mal havido. Nas invocações inicial e final do Rei dos séculos, na descrição da vida feliz das aldeias e do triunfo do missionário, no grito de vitóriacontra a superstição e a heresia, está toda a alma de Anchieta, alma de santo, alma de apóstolo e alma de poeta cristão, que só aspira para o Brasil os séculos de ouro da fé e da civilização católica. (p.40-41)
}

Daí o fechamento do poema prevendo os "séculos de ouro" quando "as gentes brasílicas" seguirem a doutrina de Cristo. É o poeta-missionário que se desdobra nesses versos, mas é também o humanista e o conquistador. A "guerra santa" só teria fim quando os brasis estivessem sujeitados ao domínio luso. Onde ficaria então o "amor ao próximo" proclamado pela Companhia de Jesus? As guerras, de que trata o poema, seriam uma imposição de Cristo aos cristãos para revelar ao mundo inteiro a vitória do bem contra o mal. E nessa luta, os índios são colocados em condição subalterna, correspondendo ao próprio satanás que deveria ser exterminado da face da terra.

As Escrituras Sagradas, citadas no poema, servem para reforçar a tese de que já estava escrito que o índio deveria ser convertido ao cristianismo. Os heróis não fizeram mais do que cumprir uma determinação divina.

A intensa alusão à mitologia pagã, num discurso jesuítico, leva-nos a concluir que Anchieta sabia da importância da inclusão dessas entidades num contexto cristão e bíblico para que a sua obra surtisse efeito universal. Ele não se ateve apenas ao mito cristão, mas trouxe para o seu poema elementos pagãos que, já em sua época, serviam como recurso estético na criação das grandes obras épicas. Os grandes autores épicos 
devem ter influenciado muito o canarino na criação deste poema, a ponto de tomar os mitos pagãos, entrelaçá-los aos cristãos, criando uma epopéia que, ao mesmo tempo que resgata o espírito de cruzada, tão comum na Idade Média, prenuncia uma nova concepção épica que vai se cristalizar com $\underline{\text { Os Lusíadas. }}$

Os versos anchietanos atendem às características épicas sem, contudo, trair a sua formação missionária e a ideologia dos cruzados. Tomando os elementos pagãos que refletem fenômenos naturais, utilizando-se de alguns epítetos já cristianizados pela Renascença, o poeta-missionário ousou entrelaçar todos esses elementos na criação de uma epopéia que se propunha a divulgar, em terras brasílicas, o nome de Cristo Rei.

Importante ressaltar que é nesse herói divino (Cristo) que reside a grande inovação anchietana, elemento básico que vai se opôr a mimese clássica da Renascença. No tocante a esse aspecto, o poema em estudo se aproxima das epopéias medievais, mas abre uma nova perspectiva épica a partir do momento em que o poeta/narrador lança mão das entidades pagãs na configuração de um novo discurso épico. Aqui servem como exemplo as palavras do professor Anazildo Vasconcelos da Silva:

\begin{abstract}
As epopéias medievais apresentam em cada lugar onde surgiram, uma identificação com as raízes culturais emergentes, representam manifestações específicas de matérias épicas, aportam elementos estruturais ao modelo renascentista, distinguindo-se da manifestação clássica, mas não chegam a constituir uma nova estrutura definida. Os elementos aportados, como o maravilhoso cristão, a elaboração lírica dentro do mundo narrado, a projeção do poeta/narrador no mundo narrado etc. só definirão uma nova manifestação do discurso épico com $\underline{\text { Os }}$ Lusíadas. ${ }^{\text {ii }}$
\end{abstract}

Segundo José Aderaldo Castello, o julgamento desse poema "é de grande importância para a reapreciação do nosso século XVI literário". (CASTELLO, José Aderaldo. As manifestações literárias do período colonial. São Paulo, Cultrix, 1981, p.55).

Nesse poema, Anchieta deixa de lado a catequese e se propõe a cantar os feitos de um herói, criado no século XVI, em terras brasílicas. O herói dessa época, na visão do colonizador, só poderia ser um nobre português, católico, que estivesse disposto a combater contra os infiéis em nome de Cristo. Para isso, reveste-o de uma auréola divina que o torna infalível nos combates. É a força do mito cristão que se sobrepõe a todos os outros mitos, abarcando-os e reduzindo-os a uma única força, que é Deus, ou como queiram, Tonans.

Há, em De Gestis Mendi Saa, o gosto pelas pelejas impossíveis e fantásticas que só obteriam bons resultados se houvesse uma força maior que superasse os poderes humanos. Esse tipo de luta descomunal percorre todo o poema e culmina na tomada do Forte de Villegaignon, conforme se pode observar nos versos que se seguem:

Ipse locum praetor contemplans maximus omnem, Quem nullo vires possent evertere ferro Humanae, aeterno dat toto ex pectore laudes Voce sonante Deo, qui turrem arcemque superbam 
Artigo de Demanda Contínua

Ceperit, atque sua virtute fugaverit hostes.(p. 164)

Tradução:

O próprio governador, olhando todo esse posto, que forças humanas jamais com arma nenhuma poderiam arrasar, do íntimo peito canta louvores

ao Deus eterno, que tomou o monte e o forte altaneiro e com a força de seu braço afugentou o inimigo. (p. 165)

Esses versos denunciam que "forças humanas jamais poderiam tomar o forte e expulsar os inimigos. O "governador", como é tratado aqui, "Canta louvores / ao Deus eterno" para interceder a seu favor. Portanto, o mito cristão se manifesta através do próprio ritual feito por Mem de Sá, tornando possível a conquista do forte.

Esse tipo de manifestação mítica é constante em toda a narrativa porque, além de se tratar de uma epopéia cristã, revela o discurso típico de um jesuíta que procurou, nesse poema, louvar os feitos de Mem de Sá, colocando-o na galeria dos heróis épicos como uma representação de Cristo Rei. 


\section{Conclusão}

Deve-se registrar que, apesar de ser uma epopeia cristã, com algumas semelhanças com as épicas medievais, não significa propriamente que esteja inserida dentro de um contexto medieval. Anchieta, nesse poema, entrelaça a Idade Média, o Renascimento, o Maneirismo e o Barroco na criação de uma epopeia típica do nosso primeiro período colonial. Estes estilos entrelaçados se harmonizam com o tipo de colonização implantada em " terras brasílicas". A guerra santa e o espírito de conquista se entrelaçam e desencadeiam uma literatura de medo e de terror. Portanto, se "as palavras e os nomes são nós", conforme nos afirma Gustav René Hocke, a literatura jesuítica, especificamente a do padre José de Anchieta, encontra-se impregnada de "nós" que precisam ser desatados para a verdadeira afirmação de nossa identidade cultural.

Podemos, portanto, afirmar que, de acordo com a reflexão sobre as diferentes propostas de epopéia e com o resgate da perspectiva crítica evolutiva da época ocidental, $D e$ Gestis Mendi Saa é uma epopeia legítima que, ao mesmo tempo, encerra o ciclo épico medieval e abre o ciclo épico renascentista. 


\section{Notas}

${ }^{1}$ CUNHA, H. P. p. $110-111$

${ }^{2}$ SILVA, A.V. p. 22

\section{Referências}

CARDOSO Padre Armando, ANCHIETA, S.J., José de. De Gestis Mendi Saa. Comissão Nacional para as comemorações do Dia de Anchieta. São Paulo: 1970.

SILVA, Anazildo Vasconcelos da. Semiotização literária do discurso. Rio de Janeiro, Elo, 1984

CUNHA Helena Parente. Os Gêneros Literários In. PORTELLA, Eduardo et alii.Teoria literária. 4.ed., Rio de Janeiro, Tempo Brasileiro, 1991. 